\title{
Deformation-induced changeable Young's modulus with high strength in $\beta$-type Ti-Cr-O alloys for spinal fixture
}

\author{
$\underline{\text { Huihong Liu }^{\mathrm{a}}}$, Mitsuo Niinomi ${ }^{\mathrm{b}} *$, Masaaki Nakai ${ }^{\mathrm{b}}$, Junko Hieda $^{\mathrm{b}}, \mathrm{Ken}_{\mathrm{Cho}}{ }^{\mathrm{b}}$ \\ ${ }^{a}$ Graduate Student, Department of Materials Science, Graduate School of Engineering, \\ Tohoku University, Sendai 980-8579, Japan \\ ${ }^{b}$ Institute for Materials Research, Tohoku University, Sendai 980-8577, Japan
}

\begin{abstract}
In order to meet the requirements of the patients and surgeons simultaneously for spinal fixation applications, a novel biomedical alloy with a changeable Young's modulus, that is, with a low Young's modulus to prevent the stress-shielding effect for patients and a high Young's modulus to suppress springback for surgeons, was developed. In this study, the chromium and oxygen contents in ternary $\mathrm{Ti}-(11,12$ mass $\%) \mathrm{Cr}-(0.2,0.4,0.6$ mass $\%) \mathrm{O}$ alloys were optimized in order to achieve a changeable Young's modulus via deformation-induced $\omega$-phase transformation with good mechanical properties.
\end{abstract}

The Young's moduli of all the examined alloys increase after cold rolling, which is attributed to the deformation-induced $\omega$-phase transformation. This transformation is suppressed by oxygen but enhanced with lower chromium content, which is related to the $\beta$ (bcc)-lattice stability. Among the examined alloys, the Ti-11Cr-0.2O alloy shows a low Young's modulus of less than $80 \mathrm{GPa}$ in the solution-treated (ST) condition and a high Young's modulus of more than $90 \mathrm{GPa}$ in the cold rolled 
(CR) condition. The Ti-11Cr-0.2O alloy also exhibits a high tensile strength, above $1000 \mathrm{MPa}$, with an acceptable elongation of $\sim 12 \%$ in the ST condition. Furthermore, the Ti-11Cr- $0.2 \mathrm{O}$ alloy exhibits minimal springback. This value of springback is the closest to that of Ti64 ELI alloy among the compared alloys. Therefore, the Ti- $11 \mathrm{Cr}-0.2 \mathrm{O}$ alloy, which has a good balance between large changeable Young's modulus, high tensile strength, good plasticity, and minimal springback, is considered to be a potential candidate for spinal fixation applications.

Keywords: Ternary Ti-Cr-O alloys, changeable Young's modulus, athermal $\omega$ phase, deformation-induced $\omega$-phase transformation, springback 


\section{Introduction}

Titanium and its alloys have been widely used for biomedical applications such as for fabricating bone plates, hip joints, dental roots, and spinal fixation devices because of their favorable mechanical properties, excellent biocompatibility, corrosion resistance, and low Young's modulus. For instance, commercially pure Ti (CP Ti) and Ti-6Al-4V extra-low interstitial alloy (Ti64 ELI), both of which are currently widely used in the biomedical fields, have Young's moduli of approximately $105 \mathrm{GPa}$ and $110 \mathrm{GPa}$ (Niinomi, 2003; Pilliar, 1991), respectively. These values are much lower than that of SUS 316L stainless steel ( 200 GPa) (Niinomi, 2003; Pilliar, 1991) and Co-Cr-Mo alloy ( 230 GPa) (Niinomi, 2002), which are presently in practical use. However, the Young's moduli of CP Ti ( $\alpha$-type) and Ti64 alloy $((\alpha+\beta)$-type) are still much higher than that of human bone ( 10-30 GPa) (Rho et al., 1997), and this higher Young's modulus will introduce a stress-shielding effect, leading to bone absorption (Sumitomo et al., 2008). Therefore, extensive efforts have been made and many new $\beta$-type titanium alloys, which have lower Young's moduli ( 40-60 GPa) (Hao et al., 2006; Kuroda et al., 1998; Matsumoto et al., 2005) than those of $\alpha$-type or $(\alpha+\beta)$-type titanium alloys, have been developed in order to prevent this stress-shielding effect. Among the $\beta$-type titanium alloys developed, Ti-29Nb-13Ta-4.6Zr (TNTZ) (Kuroda et al., 1998), which shows good corrosion resistance, excellent biocompatibility, and a low Young's modulus ( $60 \mathrm{GPa})$, is considered to be a promising candidate for next-generation biomedical use.

However, in spinal fixation devices, there are new requirements for biomaterials intended for use as implant rods. Because surgeons need to bend the implant rods to conform to the curvature of the patient's spine within a small space for in-situ spine contouring (Nakai et al., 2011; Steib et al., 
2004), the amount of springback of the implant rods should be sufficiently low to allow for easy operation by surgeons. Hence, a high Young's modulus is required for materials in order to suppress springback. On the other hand, the implant rods should also have a low Young's modulus in order to prevent the stress-shielding effect, combined with good mechanical properties and excellent biocompatibility, which benefits patients. That is, the implant rods used in spinal fixture should have a low Young's modulus, good mechanical properties, excellent biocompatibility and small springback for satisfying the requirements of both surgeons and patients simultaneously. To accomplish this, the implant rod is required to have such a "changeable Young's modulus"; that is the local Young's modulus of the deformed part of the rod increases significantly by deformation, while the rest part remains a low Young's modulus. Among the developed metallic biomaterials, SUS 316L which exhibits a high Young's modulus, hampers magnetic resonance imaging (MRI) diagnosis under strong magnetic condition (Hanawa, 2010) and the nickel (Ni) in SUS 316L is allergenic (Es-Souni et al., 2005); Ti64 ELI has a high Young's modulus and toxicity from aluminum (Al) (Boyce et al., 1992) and vanadium (V) (Domingo, 2002); TNTZ possesses only moderate mechanical properties (Kuroda, 1998); CoCrMo (Niinomi, 2002) has an extremely high Young's modulus ( 230 MPa) and the nickel (Ni) in it is a high risk element for allergy. Moreover, the common problem is that none of the above alloys has such a "changeable Young's modulus" to meet the conflicting requirements of both surgeons and patients in spinal fixture. Therefore, a novel type of biomaterial with such a changeable Young's modulus in addition with good mechanical properties and excellent biocompatibility needs to be developed for spinal fixation applications.

Phase transformations can provide an effective way to modify the microstructure and 
mechanical properties of titanium and its alloys. Structural instability, which may cause phase transformation, can be triggered either by alloying the Ti with d-electron-rich transition metal (TM) elements or by applying high pressure (Hao et al.,2007; Sikka et al., 1982; Vohra and Spencer, 2001). For certain metastable $\beta$-type titanium alloys, nonequilibrium phases such as $\alpha^{\prime}, \alpha^{\prime \prime}$, and $\omega$ phase can appear in the $\beta$ matrix during deformation (Talling et al., 2009; Wood, 1963). The $\omega$ phase has a higher Young's modulus than the $\beta$ phase (Abdel-Hady et al., 2006); thus, if the $\omega$ phase appears in the deformed part of the $\beta$-type titanium-alloy implant rod via bending deformation during spinal fixation surgery, a high Young's modulus would be obtained for the deformed part, while the Young's modulus of the non-deformed part would remain low. That is, the changeable Young's modulus can be achieved by a deformation-induced $\omega$-phase transformation in metastable $\beta$-type titanium alloys. In addition, $\beta$-type titanium alloys have low Young's moduli, good mechanical properties, and excellent corrosion resistance (Niinomi, 2003; Zhao et al., 2012b). Therefore, metastable $\beta$-type titanium alloys are chosen for this research.

It has been reported that $\omega$ phase can be induced by deformation at room temperature in Ti-V, Ti-Fe, Ti-Mo, and Ti-Cr metastable $\beta$-type titanium alloys (Hanada and Izumi, 1986a, 1986b, 1987; Kuan et al., 1975; Matsumoto et al., 2006; Oka and Taniguchi, 1979). The development of a material with a changeable Young's modulus via deformation-induced $\omega$-phase transformation and good biocompatibility has also been investigated in Ti-Cr, Ti-Mo, and Ti-30Zr-(Cr, Mo) alloys (Zhao et al., 2012a, 2012b; Zhao et al., 2011b). Among all the examined alloys, the Ti-12Cr alloy (Zhao et al., 2012b) has the largest changeable Young's modulus. According to the results reported by Zhao et al. (2012b), decreasing the chromium content ( $\beta$ stabilizing element) in Ti-(10-12) $\mathrm{Cr}$ 
alloys can reduce the $\beta(\mathrm{bcc})$-lattice stability, which increases the total amount of the $\omega$ phase. These $\omega$ phase include the athermal $\omega$ phase formed during quenching and the deformation-induced $\omega$ phase caused by cold rolling. This result suggests that lower chromium content is beneficial for enhancing the $\omega$ phase transformation in Ti-(10-12) Cr alloys. However, among these two types of $\omega$ phase, the amount of the athermal $\omega$ phase could increase with the decreasing of chromium content in Ti-(10-12)Cr alloys, thereby increasing the Young's moduli of the alloys prior to deformation (Zhao et al., 2012b). Moreover, based on the results reported by zhao et al. (2012b), it could be concluded that the suppression of the athermal $\omega$ phase is likely to play a positive effect for enhancing the deformation-induced $\omega$-phase transformation. Therefore, if the formation of the athermal $\omega$ phase in Ti-Cr alloy with a lower chromium content could be suppressed, not only a low Young's modulus will be remained in the alloy before deformation, but also an enhancement on the deformation-induced $\omega$-phase transformation could be expected. It has been widely reported that the athermal $\omega$ phase in titanium alloys can be suppressed by the addition of oxygen (de Fontaine et al., 1971; Qazi et al., 2005). Thus, for this study, oxygen is added into the metastable $\beta$-type Ti-Cr alloys to suppress the athermal $\omega$ phase and the chromium and oxygen concentrations are varied in order to achieve a low Young's modulus before deformation and a high Young's modulus after deformation. Further, it is known that high strength is an essential requirement from the viewpoint of practical applications. As a low cost and easily available element, oxygen has a strong solid solution-strengthening effect which can significantly improve the strength of alloys. On the other hand, although chromium is toxic and elicits an allergic response, the toxicity of chromium is mainly from the chromium ions $\left(\mathrm{Cr}^{3+}, \mathrm{C}^{6+}\right)$ rather than the metal (Shanker et al., 2005). Chromium 
is known to control the anodic activity of alloys and increase the tendency of titanium to passivate (Donachie, 2000). The passive films formed on the titanium alloys can maintain a high corrosion resistance of the alloys (Hanawa et al., 1998; Ong et al., 1995; Zhao et al., 2012b) and prevent the chromium ions to release from the alloys surfaces (Zhao et al., 2012b). It has been reported (Zhao et al., 2012b) that the Ti-12Cr alloy exhibits high corrosion resistance and high cytocompatibility. Moreover, oxygen is considered to be a biocompatible element and not risky to human body (Geng et al., 2011). Therefore, Ti-Cr-O alloy system is suitable for use in spinal fixture from the viewpoint of biocompatibility.

In this study, the chromium and oxygen contents in ternary Ti-Cr-O alloys were optimized to achieve a large changeable Young's modulus with good mechanical properties for spinal fixation applications.

\section{Experimental procedures}

\subsection{Materials preparation}

A series of ternary Ti-(11, 12 mass $\%) \mathrm{Cr}-(0.2,0.4,0.6$ mass $\%) \mathrm{O}$ alloys were prepared by cold crucible levitation melting in a high-purity argon atmosphere. The oxygen content was controlled by the appropriate addition of $\mathrm{TiO}_{2}$ during melting. The ingots obtained were homogenized at 1373 $\mathrm{K}$ for $21.6 \mathrm{ks}$ in an argon atmosphere, followed by ice-water quenching. The homogenized ingots were first hot forged into cuboids and then hot rolled into plates with a reduction ratio of $70 \%$ at $1273 \mathrm{~K}$ in an argon atmosphere followed by air cooling. Then, the hot-rolled plates were subjected 
to solution treatment at $1123 \mathrm{~K}$ or $1173 \mathrm{~K}$ (which temperature is selected depends on different $\beta$ transus temperature affected by alloying elements) for $3.6 \mathrm{ks}$ in vacuum and rapidly quenched in ice water. As mentioned above, the rods deform by bending during surgery operations. However, it is difficult to measure the Young's moduli of alloys after bending. In this study, therefore, cold rolling was employed as an alternative deformation mode in order to trigger a deformation-induced phase transformation so that the mechanical properties, including Young's moduli and tensile properties of alloys after deformation, could be investigated. Therefore, the solution-treated specimens were lastly subjected to cold rolling with a reduction ratio of $10 \%$ at room temperature. The solution treatment and cold rolling were labeled as ST and CR, respectively. The chemical compositions of all the designed alloys were determined by conventional chemical and gas analyses and the results are listed in Table 1.

\subsection{Microstructural analysis}

The phase constitutions of all the designed alloys were identified by X-ray diffraction analysis (XRD) using a Bruker D8 Discover 2D X-ray diffractometer with $\mathrm{Cu} \mathrm{K} \alpha$ radiation at an accelerating voltage of $40 \mathrm{kV}$ and a current of $40 \mathrm{~mA}$. The microstructures of the alloys were examined by optical microscopy (OM) (Olympus BX51), electron backscattered diffraction (EBSD) (Quanta 200 3D SEM-TSL) analysis, and transmission electron microscopy (TEM) (JEOL JEM-2000EX). For OM and EBSD observations, the specimens were mechanically polished using $\mathrm{SiC}$ waterproof emery paper of up to 2400 grit; polishing was then completed using a colloidal $\mathrm{SiO}_{2}$ suspension. The mirror-polished specimens were etched using aqueous solutions mixed with 
hydrofluoric acid (HF: 1 vol\%) and nitric acid $\left(\mathrm{HNO}_{3}: 0.5\right.$ vol\%) for $1 \mathrm{~min}$. For TEM observations, the specimens were first mechanically polished to a thickness of approximately $40 \mu \mathrm{m}$ and then dimpled to a level of approximately $10 \mu \mathrm{m}$ with a phosphor bronze ring. Finally, the dimpled specimens were ion milled to a thin foil. TEM observations were conducted at an accelerating voltage of $200 \mathrm{kV}$.

\subsection{Mechanical evaluation}

The mechanical properties of all the designed alloys were evaluated by Young's modulus measurements, tensile tests, and tensile loading-unloading tests; the tensile loading-unloading tests were carried out in order to investigate the springback of the alloys. Rectangular plate specimens with dimensions of $40 \times 10 \times 1.5 \mathrm{~mm}$ were cut from the ST and CR plates by a wire electric discharge machine for Young's modulus measurements. The longitudinal directions of these specimens were parallel to the rolling direction. The specimens were then polished with $\mathrm{SiC}$ waterproof emery paper of up to 2400 grit. The Young's moduli of the alloys were measured at room temperature in air using a free resonance method (Zhao et al., 2011a). For the tensile and tensile loading-unloading tests, specimens were cut from the ST and CR plates using a wire electric discharge machine. The cut specimens had a thickness of $1.5 \mathrm{~mm}$, a width of $3 \mathrm{~mm}$, and a gage length of $13 \mathrm{~mm}$. The longitudinal directions of these specimens were also parallel to the rolling direction. The specimens for tensile and tensile loading-unloading tests were polished using SiC waterproof papers of up to 2400 grit, and then subjected to the tests at a cross-head speed of $8.33 \times$ $10^{-6} \mathrm{~m} \mathrm{~s}^{-1}$ at room temperature in air via an Instron-type machine (Shimadzu AGS-20kNG), with strain gages attached to the gage sections of the specimens (Zhao et al., 2012a; Zhao et al., 2011a, 
2011b). For Young's modulus measurements and tensile tests, three specimens were tested in order to minimize the experimental errors.

The tensile loading-unloading tests were performed in order to investigate the effect of changeable Young's modulus on springback, in which the strain on the sample was increased from 1\% to $10 \%$ in steps of $1 \%$. In practical applications, springback varies with the strength of the rod. Therefore, in this study, the springback per unit stress was investigated in order to eliminate the effect of strength on springback. Further, the ratio (R) of springback (recovery strain) to applied strain, rather than the amount of springback, was examined in order to reduce the strain error during tests (Zhao et al., 2011b). This ratio R can be calculated as follows:

$$
\mathrm{R}=\left(\left(\varepsilon_{i 2}-\varepsilon_{i 3}\right) /\left(\varepsilon_{i 2}-\varepsilon_{i 1}\right)\right) / \sigma_{i}
$$

The strains used for the calculation are illustrated in Fig. 1, where $\varepsilon_{i 1}$ is the initial strain, $\varepsilon_{i 2}$ is the loading strain, $\varepsilon_{i 3}$ is the unloading strain of the $i$ th cycle, and $\sigma_{i}$ is the tensile stress corresponding to the applied strain.

\section{Results and Discussion}

\subsection{Microstructures}

Figure 2 shows the XRD profiles of all the examined $\mathrm{Ti}-(11,12) \mathrm{Cr}-(0.2,0.4,0.6) \mathrm{O}$ alloys subjected to solution treatment (ST) and cold rolling (CR). The figure shows that only the peaks corresponding to the $\beta$ phase are detected in all the alloys under both ST and CR conditions; no other phase, including the $\omega$ phase, is detected.

Optical micrographs of all the alloys subjected to ST and CR are shown in Fig. 3. All the alloys 
subjected to ST consist of equiaxed grains with an average size of approximately $300 \mu \mathrm{m}$, as shown in Figs. 3a-f. After CR, lentoid structures with width of approximately $20 \mu \mathrm{m}$ are observed in the equiaxed grains of all the alloys, as shown in Figs. $3 a^{\prime}-f^{\prime}$. In addition, with increasing of oxygen content of $0.2,0.4$, and 0.6 mass $\%$, the volume fractions of the lentoid structures in the cold-rolled alloys decrease from approximately $8 \%$ to $6 \%$ and then to $3 \%$, respectively, as measured by conventional image analysis.

Figure 4 shows the EBSD results of the Ti- $11 \mathrm{Cr}-0.2 \mathrm{O}$ and Ti- $12 \mathrm{Cr}-0.6 \mathrm{O}$ alloys after CR. The lentoid structures can be observed in the orientation image maps of both alloys owing to the different colors with the matrix (Figs. $4 b$ and $b^{\prime}$ ). The different colors imply that the crystallographic features of the lentoid structures, including the crystal structures and/or the crystallographic orientations, differ from those of the matrix. Along the arrows seen in the figure, the crystallographic misorientations between the lentoid structures and the matrix can be measured (Figs. 4d and $\mathrm{d}^{\prime}$ ). Combined with the XRD results, it is concluded that the lentoid structures have the same bcc crystal structure as the $\beta$ matrix but a different crystal orientation. The results also show that the lentoid structures are composed of several parts with different crystal orientations, including continuous and discontinuous crystal rotations. According to the orientation image maps, the grain boundary maps of both alloys can be obtained (Figs. $4 c$ and $c^{\prime}$ ), in which the red lines correspond to the boundaries of the lentoid structures, suggesting that the misorientation angles of the boundaries are approximately $10^{\circ}$ around the $\langle 110\rangle \beta$ crystal direction. These results indicate that the lentoid structures are different from the $\{332\}<113>$ mechanical twinning that is often observed in cold-worked $\beta$-type titanium alloys, which have a misorientation angle of $50.5^{\circ}$ around 
the <110> $\beta$ direction (Furuta et al., 2005; Hanada and Izumi, 1987). The abovementioned characteristics of the lentoid structures correspond to one kind of band, called the kink band (Yang et al., 2010). Such bands, which are seems to be kink bands, are observed in all the examined alloys subjected to CR. The further analysis is needed to confirm these bands being kink bands.

Figure 5 shows the selected-area electron diffraction patterns of the Ti- $(11,12) \mathrm{Cr}-(0.2,0.4$, 0.6)O alloys subjected to ST and CR. For ST conditions, sporadic weak spots related to the athermal $\omega$ phase combined with the spots derived from the $\beta$ phase can be detected only in the electron diffraction patterns of the Ti- $11 \mathrm{Cr}-0.2 \mathrm{O}$ and Ti-12Cr-0.2O alloys (Figs. 5a and b). This indicates that only a small amount of athermal $\omega$ phase forms in the Ti- $11 \mathrm{Cr}-0.2 \mathrm{O}$ and $\mathrm{Ti}-12 \mathrm{Cr}-0.2 \mathrm{O}$ alloys upon water quenching. As the oxygen content increases, the sporadic spots corresponding to the athermal $\omega$ phase disappear and only circular diffuse streaks related to the $\omega$ phase are observed in the Ti- $(11,12) \mathrm{Cr}-0.4 \mathrm{O}$ alloys (Figs. $5 \mathrm{c}$ and d). The intensities of these circular diffuse streaks are weakened in the Ti-(11, 12)Cr-0.6O alloys (Figs. 5e and f). These results suggest that oxygen can suppress the athermal $\omega$ phase in Ti-Cr-O alloys, which is consistent with the results of previous researches (de Fontaine et al., 1971; Qazi et al., 2005). After CR, the intensities of the $\omega$ reflections of all the alloys increase, and spots that correspond to the $\omega$ phase, combined with spots derived from the $\beta$ phase, are observed in the patterns of all the examined alloys (Figs. $5 a^{\prime}-f^{\prime}$ ), suggesting that deformation-induced $\omega$-phase transformation by cold rolling occurs in all the alloys. Among the examined alloys subjected to CR, the intensities of the $\omega$ reflections increase with decreasing oxygen or chromium content. The Ti- $11 \mathrm{Cr}-0.2 \mathrm{O}$ alloy shows the highest intensity of $\omega$ reflections.

\subsection{Mechanical properties}




\subsubsection{Young's modulus}

Figure 6 shows the Young's moduli of the Ti- $(11,12) \mathrm{Cr}-(0.2,0.4,0.6) \mathrm{O}$ alloys subjected to ST and CR. For ST conditions and the same chromium content, the Young's moduli of the alloys increase with increasing oxygen content. This is attributed to the solid solution-strengthening effect of oxygen. Further, at the same oxygen content, the Young's moduli of the Ti- $11 \mathrm{Cr}-0.2 \mathrm{O}$ and Ti-12Cr-0.2O alloys are almost the same, whereas the Ti-12Cr-0.4O and Ti-12Cr-0.6O alloys have slightly higher Young's moduli as compared with the Ti- $11 \mathrm{Cr}-0.4 \mathrm{O}$ and $\mathrm{Ti}-11 \mathrm{Cr}-0.6 \mathrm{O}$ alloys, respectively. The reasons are as follows. For the Ti- $11 \mathrm{Cr}-0.2 \mathrm{O}$ and $\mathrm{Ti}-12 \mathrm{Cr}-0.2 \mathrm{O}$ alloys, there is still a small amount of athermal $\omega$ phase formed in the ST condition, so that the Young's moduli of the alloys are influenced by the combined effects of the athermal $\omega$ phase, which can be suppressed by higher chromium content relating to the $\beta$-lattice stability, and the solid solution-strengthening effect of chromium. However, because almost no athermal $\omega$ phase forms in the Ti-(11, 12)Cr- $(0.4$, 0.6)O alloys, the solid solution-strengthening effect of chromium becomes the primary reason for the change in Young's modulus. After CR, the Young's moduli of all the designed alloys increase as compared with those subjected to ST. It has been mentioned above that the deformation-induced $\omega$-phase transformation occurs in all the designed alloys according to TEM observations and the authors (Zhao et al., 2012a, 2012b; Zhao et al., 2011b) have reported the deformation-induced $\omega$ phase plays a role in increasing the Young's moduli of the alloys. Thus, it is concluded that the increase in Young's modulus is owing to the deformation-induced $\omega$-phase transformation occurring in all the designed alloys during cold rolling. Further, under the same chromium content, the degree of increase in Young's modulus of the alloys gradually decreases with increasing oxygen content, 
whereas under the same oxygen content, the degree of increase in Young's modulus is larger in the alloys with lower chromium content. It is known that the degree of increase in Young's modulus depends on the amount of the deformation-induced $\omega$ phase (Zhao et al., 2012a, 2012b). Therefore, it is concluded that the deformation-induced $\omega$-phase transformation via cold rolling in $\mathrm{Ti}-\mathrm{Cr}-\mathrm{O}$ alloys is suppressed by the addition of oxygen, whereas it is improved with lower chromium content. It has been determined that the formation of both athermal $\omega$ phase and deformation-induced $\omega$ phase involve an athermal mechanism known as the lattice collapse mechanism, which is illustrated in Fig. 7 in detail (Banerjee and Mukhopadhyay, 2007). As observed in the figure, the $\omega$ lattice can be derived from the $\beta$-bcc lattice by collapsing a pair of neighboring (111) planes (1 and 2, as shown in Fig. 7) via atomic displacement into the intermediate position (marked as 1.5), while keeping planes 0 and 3 unchanged. That is, the collapse of planes depends on the atomic displacement. Oxygen, as an interstitial element, will occupy the interstitial site of the bcc lattice, thereby increasing the resistance to atomic displacement and suppressing the formation of both athermal $\omega$ phase and deformation-induced $\omega$ phase. Several investigators (de Fontaine et al., 1971; Williams et al., 1973) have also indicated that the collapse of planes results from the interaction of linear defects created from the atomic displacement in the $\beta$ phase to $1 / 3$ unit distance toward neighboring atoms, and they suggest that oxygen, as an interstitial atom, may pin the linear defects, thus hindering the collapse of the (111) $\beta$ planes. Chromium is considered to be a $\beta$ lattice stabilizing element. The decrease of chromium content in $\beta$ titanium alloys may cause $\beta$ lattice instability with respect to the lattice disturbance, which is responsible for the athermal atomic displacement (de Fontaine et al., 1971). Thus, decreasing the chromium content may improve the 
atomic displacement and enhance the formation of both athermal $\omega$ phase and deformation-induced $\omega$ phase.

In this study, the Ti-11Cr- $0.2 \mathrm{O}$ alloy exhibits a low Young's modulus of less than $80 \mathrm{GPa}$ in the ST condition. This value is much lower than those of SUS 316L ( 200 GPa), CP Ti ( 105 GPa), and Ti64 ELI ( 110 GPa) which are widely used in biomedical applications presently. The Ti-11Cr-0.2O alloy also shows a high Young's modulus of more than $90 \mathrm{GPa}$ in the CR condition. Therefore, among the examined alloys, the Ti- $11 \mathrm{Cr}-0.2 \mathrm{O}$ alloy shows the largest changeable Young's modulus caused by deformation which is preferred for satisfying the conflicting requirements of both surgeons and patients in spinal fixation applications.

\subsubsection{Tensile properties}

Figure 8 shows the tensile properties of the Ti- $(11,12) \mathrm{Cr}-(0.2,0.4,0.6) \mathrm{O}$ alloys subjected to ST and CR. In both ST and CR conditions, the tensile strength of all the alloys increases and the elongation decreases with increasing oxygen content because of the solid solution-strengthening effect of oxygen. For ST conditions, comparing alloys with the same oxygen content but different chromium content, it is noticed that the higher tensile strength is obtained in the alloys with lower chromium content. This can likely be attributed to the fact that the deformation-induced $\omega$-phase transformation, which has a positive effect on improving the tensile strength of the alloys (Zhao et al., 2012a, 2012b), occurs more extensively during the tensile-testing process in the alloys with lower chromium content. After CR, the tensile strength of all the alloys increases, whereas the elongation decreases. This is because of the internal stress field and deformation effects (such as tangled dislocations) due to cold rolling. An exception is shown here that the yield strength of the 
cold rolled Ti- $11 \mathrm{Cr}-0.4 \mathrm{O}$ and $\mathrm{Ti}-11 \mathrm{Cr}-0.6 \mathrm{O}$ alloys slightly decrease compared with that of the solution treated alloys. This is possibly owing to the microstructure inhomogeneity with regard to the inhomogeneity of stress distribution in the cold rolled alloys. Further, the elongation of all the alloys shows the same variation in terms of the volume fraction of kink bands as is observed in cold-rolled alloys: i.e., decreasing elongation with increasing oxygen content. These results indicate that the elongation of the alloys is closely related to the deformation mechanism and the above results are consistent with the theory (Sakai et al., 2009; Yang et al., 2010) which illustrates that kink bands are local crystallographic bands with an arbitrary rotating degree, and kinking is a type of cooperative deformation mechanism; the formation of kink bands can improve the deformability of the crystal by stress relaxation and crystal reorientation. Among the examined alloys, the Ti-11Cr-0.2O alloy shows high tensile strength, above $1000 \mathrm{MPa}$ and $1080 \mathrm{MPa}$ in the ST and CR conditions, respectively. These values are higher than that of SUS 316L ( $\sim 580 \mathrm{MPa}), \mathrm{CP}$ Ti $(\sim 450$ MPa), Ti64 ELI ( 920 MPa) (Niinomi, 1998; Pilliar, 1991; Zhao et al., 2012b) which are currently applied in practical biomedical use, and TNTZ ( 510 MPa) (Kuroda et al., 1998) which has been developed for biomedical applications. The Ti-11Cr- $0.2 \mathrm{O}$ alloy also exhibits an elongation of $\sim 12 \%$ in the ST condition, and $\sim 10 \%$ in the CR condition. It is known that the elongation of biomedical titanium alloys is distributed between $\sim 10$ and 20\% (Niinomi, 1998). These values which are similar with that of Ti64 ELI alloy (Niinomi, 1998), are acceptable for the biomedical applications.

\subsubsection{Springback}

In order to investigate the effect of changeable Young's modulus on springback, tensile loading-unloading tests were performed on the Ti-11Cr-0.2O alloy, which has the largest 
changeable Young's modulus and good mechanical properties among all the examined alloys. TNTZ (Kuroda et al., 1998), which exhibits a low Young's modulus with good biocompatibility, Ti-30Zr-3Cr-3Mo (Zhao et al., 2011b), Ti-17Mo (Zhao et al., 2012a), Ti-12Cr (Zhao et al., 2012b) alloys which have been recently developed for spinal fixation applications and have changeable Young's moduli, and Ti64 ELI which is currently widely used in practical use, were chosen for comparison.

Figure 9 shows the comparison profiles of the ratio of springback per unit stress as a function of the applied strain for the TNTZ, Ti-30Zr-3Cr-3Mo, Ti-17Mo, Ti-12Cr, Ti-11Cr-0.2O and Ti64 ELI alloys. The ratios of springback per unit stress of all the alloys show a similar trend, initially decreasing significantly, and then remaining approximately stable with the increasing applied strain. Among the above alloys, the Ti- $11 \mathrm{Cr}-0.2 \mathrm{O}$ alloy, which reaches a very low, stable value when the applied strain is greater than $2 \%$, exhibits a minimal ratio of springback per unit stress. This value is much lower than that of TNTZ, and is the closest to that of Ti64 ELI among the compared alloys.

In above, the Ti-11Cr-0.2O alloy shows a good balance between changeable Young's modulus, high tensile strength, good plasticity, and small springback. Thus, the Ti- $11 \mathrm{Cr}-0.2 \mathrm{O}$ alloy exhibits great potential for spinal fixation applications. 


\section{Conclusions}

In this study, the chromium and oxygen contents of ternary $\mathrm{Ti}-\mathrm{Cr}-\mathrm{O}$ alloys were optimized to achieve a large changeable Young's modulus with good mechanical properties for spinal fixation applications via deformation-induced $\omega$-phase transformation. The microstructures and mechanical properties of all the designed alloys were systematically examined to assess their mechanical compatibility. The springback of the optimized alloy in comparison with other developed biomedical $\beta$-titanium alloys was also investigated. The following conclusions were obtained:

(1) The Young's moduli of all the examined alloys increase after cold rolling, which is attributed to the deformation-induced $\omega$-phase transformation.

(2) Deformation-induced $\omega$-phase transformation is suppressed by oxygen, whereas it is enhanced with lower chromium content, which is related to the $\beta$-lattice stability.

(3) The Ti-11Cr-0.2O alloy shows a high tensile strength, above $1000 \mathrm{MPa}$, with an acceptable elongation of $\sim 12 \%$ in the ST condition. It also shows a higher tensile strength, $\sim 1080 \mathrm{MPa}$, with an acceptable elongation of $\sim 10 \%$ in the CR condition.

(4) Among the examined alloys, the Ti-11Cr- $0.2 \mathrm{O}$ alloy shows the largest changeable Young's modulus with good mechanical properties. Furthermore, the Ti-11Cr-0.2O alloy exhibits minimal springback. Therefore, the Ti-11Cr-0.2O alloy, which maintains a good balance between changeable Young's modulus, high tensile strength, good plasticity, and small springback, is considered a potential candidate for spinal fixation applications. 


\section{Acknowledgements}

THIS WORK WAS SUPPORTED IN PART BY INDUSTRIAL TECHNOLOGY RESEARCH GRANT PROGRAM IN 2009 FROM THE NEW ENERGY AND INDUSTRIAL TECHNOLOGY DEVElopMENT ORGANIZATION (NEDO) OF JAPAN, ADAPTABle AND SEAMLEsS Technology Transfer Program through TARget-Driven R\&D (A-STEP) FROM THE JAPAN SCIENCE AND TECHNOlOGy AGENCY (JST), Grant-in-Aid for Scientific Research from the Japan Society for the Promotion of Science (JSPS), AND the inter university cooperative research program "Innovation Research for Biosis-Abiosis Intelligent Interface" from Ministry of Sports, Culture, and Education, Japan. 


\section{References}

Abdel-Hady, M., Hinoshita, K., Morinaga, M., 2006. General approach to phase stability and elastic properties of $\beta$-type Ti-alloys using electronic parameters. Scripta. Mater. 55, 477-480.

Banerjee, S., Mukhopadhyay, P., 2007. Transformations Related to Omega Structures, in: Cahn, R.W. (Eds.), Phase Transformations: Examples from Titanium and Zirconium Alloys. Elsevier, Great Britain, pp. 474-508.

Boyce, B.F., Byars, J., McWilliams, S., Mocan, M.Z., Elder, H.Y., Boyle, I.T., Junor, B.J., 1992. Histological and electron microprobe studies of mineralisation in aluminium-related osteomalacia. J. Clin. Pathol. 45, 502-508.

de Fontaine, D., Paton, N.E., Williams, J.C., 1971. The omega phase transformation in titanium alloys as an example of displacement controlled reactions. Acta. Metall. 19, 1153-1162.

Domingo, J., 2002. Vanadium and tungsten derivatives as antidiabetic agents. Biol. Trace. Elem. Res. 88, 97-112.

Donachie, M.J., 2000. Titanium: A Technical Guide, second ed. ASM International, Materials Park, $\mathrm{OH}$.

Es-Souni, M., Es-Souni, M., Fischer-Brandies, H., 2005. Assessing the biocompatibility of NiTi shape memory alloys used for medical applications. Anal. Bioanal. Chem. 38, 557-567.

Furuta, T., Kuramoto, S., Hwang, J.H., Nishino, K., Saito, T., 2005. Elastic deformation behavior of multi-functional Ti-Nb-Ta-Zr-O alloys. Mater. Trans. 46, 3001-3007.

Geng, F., Niinomi, M., Nakai, M., 2011. Observation of yielding and strain hardening in a titanium alloy having high oxygen content. Mater. Sci. Eng. A 528, 5435-5445. 
Hanada, S., Izumi, O., 1986a. Deformation behaviour of retained $\beta$ phase in $\beta$-eutectoid Ti-Cr alloys. J. Mater. Sci. 21, 4131-4139.

Hanada, S., Izumi, O., 1986b. Transmission electron microscopic observations of mechanical twinning in metastable beta titanium alloys. Metall. Trans. A 17, 1409-1420.

Hanada, S., Izumi, O., 1987. Correlation of tensile properties, deformation modes, and phase stability in commercial $\beta$-phase titanium alloys. Metall. Trans. A 18, 265-271.

Hanawa, T., 2010. Biocompatibility and biofunctional metals for biomaterials. J. Japan. Soc. Biomater. 28, 18-26.

Hanawa, T., Asami, K., Asaoka, K., 1998. Repassivation of titanium and surface oxide film regenerated in simulated bioliquid. J. Biomed. Mater. Res. 40, 530-538.

Hao, Y.L., Li, S.J., Sun, S.Y., Yang, R., 2006. Effect of Zr and Sn on Young's modulus and superelasticity of Ti-Nb-based alloys. Mater. Sci. Eng. A 441, 112-118.

Hao, Y.L., Li, S.J., Sun, S.Y., Zheng, C.Y., Yang, R., 2007. Elastic deformation behaviour of Ti-24Nb-4Zr-7.9Sn for biomedical applications. Acta. Biomater. 3, 277-286.

Kuan, T.S., Ahrens, R.R., Sass, S.L., 1975. The stress-induced omega phase transformation in Ti-V alloys. Metall. Trans. A 6, 1767-1774.

Kuroda, D., Niinomi, M., Morinaga, M., Kato, Y., Yashiro, T., 1998. Design and mechanical properties of new $\beta$ type titanium alloys for implant materials. Mater. Sci. Eng. A 243, 244-249.

Matsumoto, H., Watanabe, H., Masahashi, N., Handa, S., 2006. Composition dependence of Young's modulus in Ti-V, Ti-Nb, and Ti-V-Sn alloys. Metall. Trans. A 37, 3239-3249. 
Matsumoto, H., Watanabe, S., Hanada, S., 2005. Beta TiNbSn alloys with low Young's modulus and high strength. Mater. Trans. 46, 1070-1078.

Nakai, M., Niinomi, M., Zhao, X.F., Zhao, X.L., 2011. Self-adjustment of Young's modulus in biomedical titanium alloys during orthopaedic operation. Mater. Lett. 65, 688-690.

Niinomi, M., 1998. Mechanical properties of biomedical titanium alloys. Mater. Sci. Eng. A 243, 231-236.

Niinomi, M., 2002. Recent metallic materials for biomedical applications. Metall. Mater. Trans. A 33, 477-486.

Niinomi, M., 2003. Recent research and development in titanium alloys for biomedical applications and healthcare goods. Sci. Technol. Adv. Mater. 4, 445-454.

Oka, M., Taniguchi, Y., 1979. 332 Deformation twins in a Ti-155 pet V alloy. Metall. Trans. A 10, 651-653.

Ong, J.L., Lucas, L.C., Raikar, G.N., Connatser, R., Gregory, J.C., 1995. Spectroscopic characterization of passivated titanium in a physiologic solution. J. Mater. Sci. Mater. Med. 6, 113-119.

Pilliar, RM., 1991. Modern metal processing for improved load-bearing surgical implants. Biomaterials 12, 95-100.

Qazi, J.I., Marquardt, B., Allard, L.F., Rack, H.J., 2005. Phase transformations in Ti-35Nb-7Zr-5Ta-(0.06-0.68)O alloys. Mater. Sci. Eng. C 25, 389-397.

Rho, J.Y., Tsui, T.Y., Pharr, G.M., 1997. Elastic properties of human cortical and trabecular lamellar bone measured by nanoindentation. Biomaterials 18, 1325-1330. 
Sakai, T., Miura, H., Yang, X., 2009. Ultrafine grain formation in face centered cubic metals during severe plastic deformation. Mater. Sci. Eng. A 499, 2-6.

Shanker, A.K., Cervantes, C., Herminia, L.T., Avudainayagam, S., 2005. Chromium toxicity in plants. Environ. Int. 31, 739-753.

Sikka, S.K., Vohra, Y.K., Chidambaram, R., 1982. Omega phase in material. Prog. Mater. Sci. 27, 245.

Steib, J.P., Dumas, R., Mitton, D., Skalli, W., 2004. Surgical correction of scoliosis by in situ contouring. Spine 29, 193-199.

Sumitomo, N., Noritake, K., Hattori, T., Morikawa, K., Niwa, S., Sato, K., Niinomi, M., 2008. Experiment study on fracture fixation with low rigidity titanium alloy. J. Mater. Sci. 19, 1581-1586.

Talling, R.J., Dashwood, R.J., Jackson, M., Dye, D., 2009. On the mechanism of superelasticity in gum metal. Acta. Mater. 57, 1188-1198.

Vohra, Y.K., Spencer, P.T., 2001. Novel gamma-phase of titanium metal at megabar pressures. Phys. Rev. Lett. 86, 3068-3071.

Williams, J.C., de Fontaine, D., Paton, N.E., 1973. The $\omega$-phase as an example of an unusual shear transformation. Metall. Trans. 4, 2701-2708.

Wood, R.M., 1963. Martensitic alpha and omega phases as deformation products in a titanium-15\% molybdenum alloy. Acta. Metall. 11, 907-914.

Yang, Y., Wu, S.Q., Li, G.P., Li, Y.L., Lu, Y.F., Yang, K., Ge, P., 2010. Evolution of deformation mechanisms of Ti-22.4Nb-0.73Ta-2Zr-1.34O alloy during straining. Acta. Mater. 58, 
2778-2787.

Zhao, X.F., Niinomi, M., Nakai, M., Hieda, J., 2012a. Beta type Ti-Mo alloys with changeable Young's modulus for spinal fixation applications. Acta. Biomater. 8, 1990-1997.

Zhao, X.F., Niinomi, M., Nakai, M., Hieda, J., Ishimoto, T., Nakano, T., 2012b. Optimization of Cr content of metastable $\beta$-type Ti-Cr alloys with changeable Young's modulus for spinal fixation applications. Acta. Biomater. 8, 2392-2400.

Zhao, X.L., Niinomi, M., Nakai, M., Ishimoto, T., Nakano, T., 2011a. Development of high Zr-containing Ti-based alloys with low Young's modulus for use in removable implants. Mater. Sci. Eng. C 31, 1436-1444.

Zhao, X.L., Niinomi, M., Nakai, M., Miyamoto, G., Furuhara, T., 2011b. Microstructures and mechanical properties of metastable Ti-30Zr-(Cr, Mo) alloys with changeable Young's modulus for spinal fixation applications. Acta. Biomater. 7, 3230-3236. 
Figure and table captions

Fig. 1. Schematic illustration of strains for calculation of the springback ratio $(R)$.

Fig. 2. XRD profiles of Ti-Cr-O alloys subjected to (a) solution treatment (ST) and (b) cold rolling $(\mathrm{CR})$.

Fig. 3. Optical micrographs of Ti-Cr-O alloys subjected to solution treatment (ST) and cold rolling (CR).

Fig. 4. EBSD analysis of Ti-12Cr-0.6O (a-d) and Ti-11Cr-0.2O (a'-d') alloys subjected to $\mathrm{CR}$ : $\left(\mathrm{a}, \mathrm{a}^{\prime}\right)$ optical micrographs, $\left(\mathrm{b}, \mathrm{b}^{\prime}\right)$ corresponding local orientation image map (OIM) figures, $\left(\mathrm{c}, \mathrm{c}^{\prime}\right) \mathrm{GB}$ maps showing boundaries with a misorientation of $10^{\circ}$ along the $<110>\beta$ direction (red lines), $\left(d, d^{\prime}\right)$ misorientations relative to the first points along the blue and red arrows in (b) and ( $\left.b^{\prime}\right)$ respectively.

Fig. 5. Selected area electron diffraction patterns of $\mathrm{Ti}-(11,12) \mathrm{Cr}-(0.2,0.4,0.6) \mathrm{O}$ alloys subjected to ST and CR: (a) Ti-11Cr-0.2O-ST, (b) Ti-12Cr-0.2O-ST, (c) Ti-11Cr-0.4O-ST, (d) Ti-12Cr-0.4O-ST, (e) Ti-11Cr-0.6O-ST, (f) Ti-12Cr-0.6O-ST, (a') Ti-11Cr-0.2O-CR, $\quad\left(b^{\prime}\right) \quad$ Ti-12Cr-0.2O-CR, $\quad\left(c^{\prime}\right) \quad$ Ti-11Cr-0.4O-CR, $\quad\left(d^{\prime}\right)$ Ti-12Cr-0.4O-CR, (e') Ti-11Cr-0.6O-CR, (f') Ti-12Cr-0.6O-CR. The beam direction is parallel to $[110] \beta$. (The ellipse with solid line or dotted line indicates that the $\omega$ spot is visible or invisible respectively in Figs. $5 \mathrm{a}$ and $\mathrm{a}^{\prime}$.)

Fig. 6. Young's moduli of Ti- $(11,12) \mathrm{Cr}-(0.2,0.4,0.6) \mathrm{O}$ alloys subjected to ST and CR. 
Fig. 7. Schematic illustration of lattice collapse mechanism (Banerjee and Mukhopadhyay, 2007).

Fig. 8. Tensile properties of Ti- $(11,12) \mathrm{Cr}-(0.2,0.4,0.6) \mathrm{O}$ alloys subjected to ST and CR.

Fig. 9. Ratio of springback per unit stress (R) as a function of applied strain for Ti-11Cr-0.2O, TNTZ (Kuroda et al., 1998), Ti-30Zr-3Cr-3Mo (Zhao et al., 2011b), Ti-17Mo (Zhao et al., 2012a), Ti-12Cr (Zhao et al., 2012b) and Ti64 ELI alloys subjected to ST.

Table 1 Nominal and analyzed chemical compositions of Ti-Cr-O alloys (mass\%) 


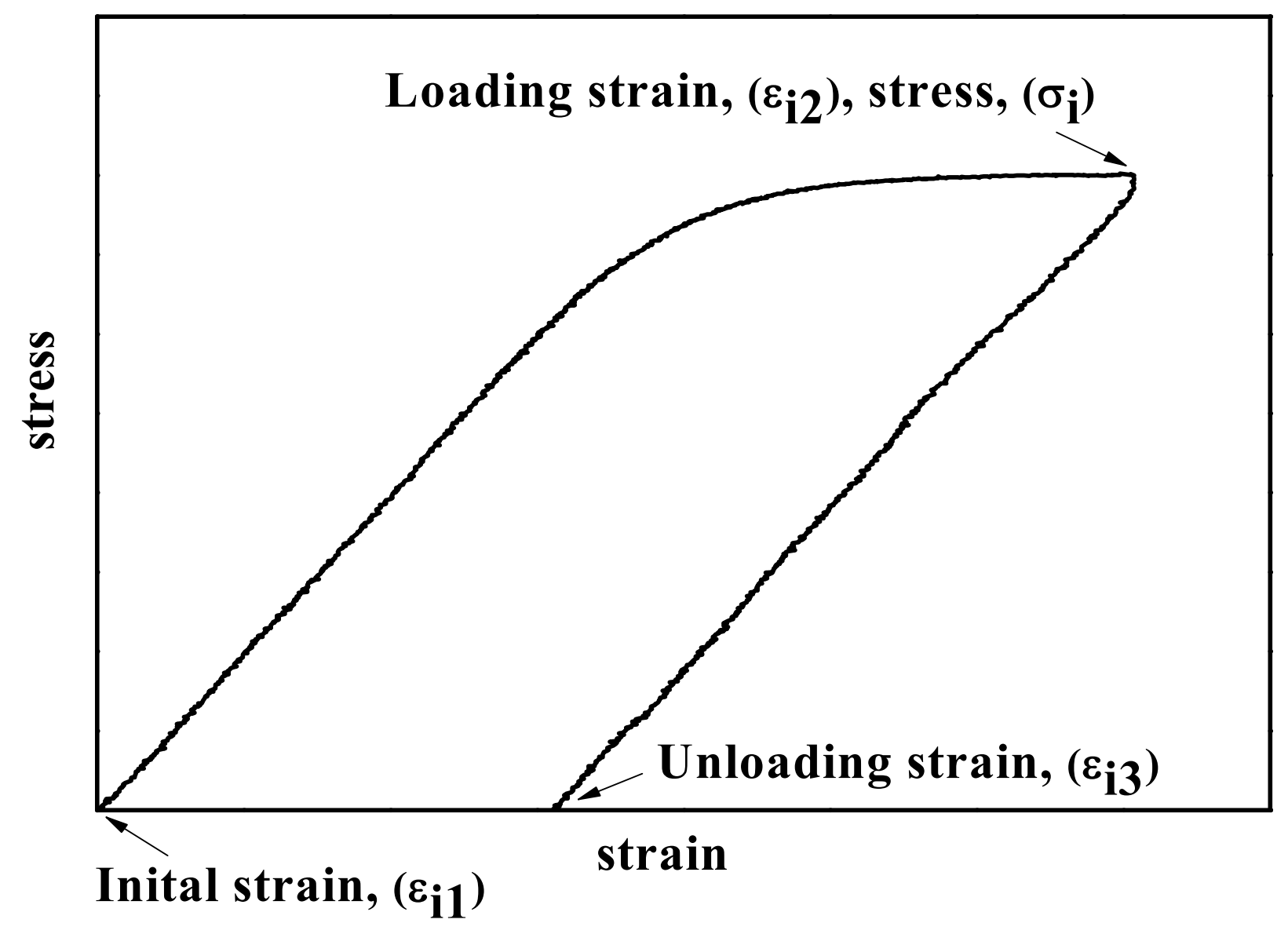

Fig. 1. Schematic illustration of strains for calculation of the springback ratio $(\mathrm{R})$. 


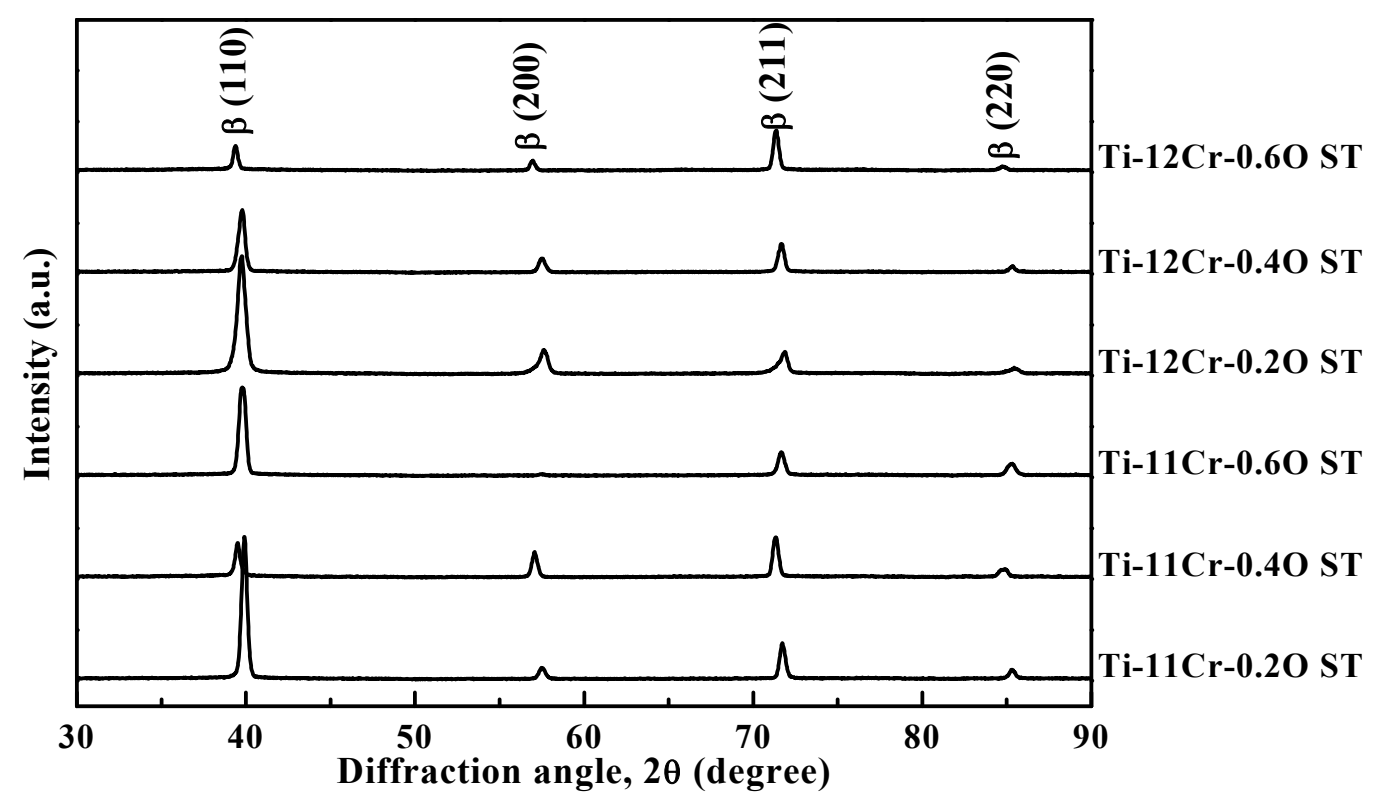

(a)

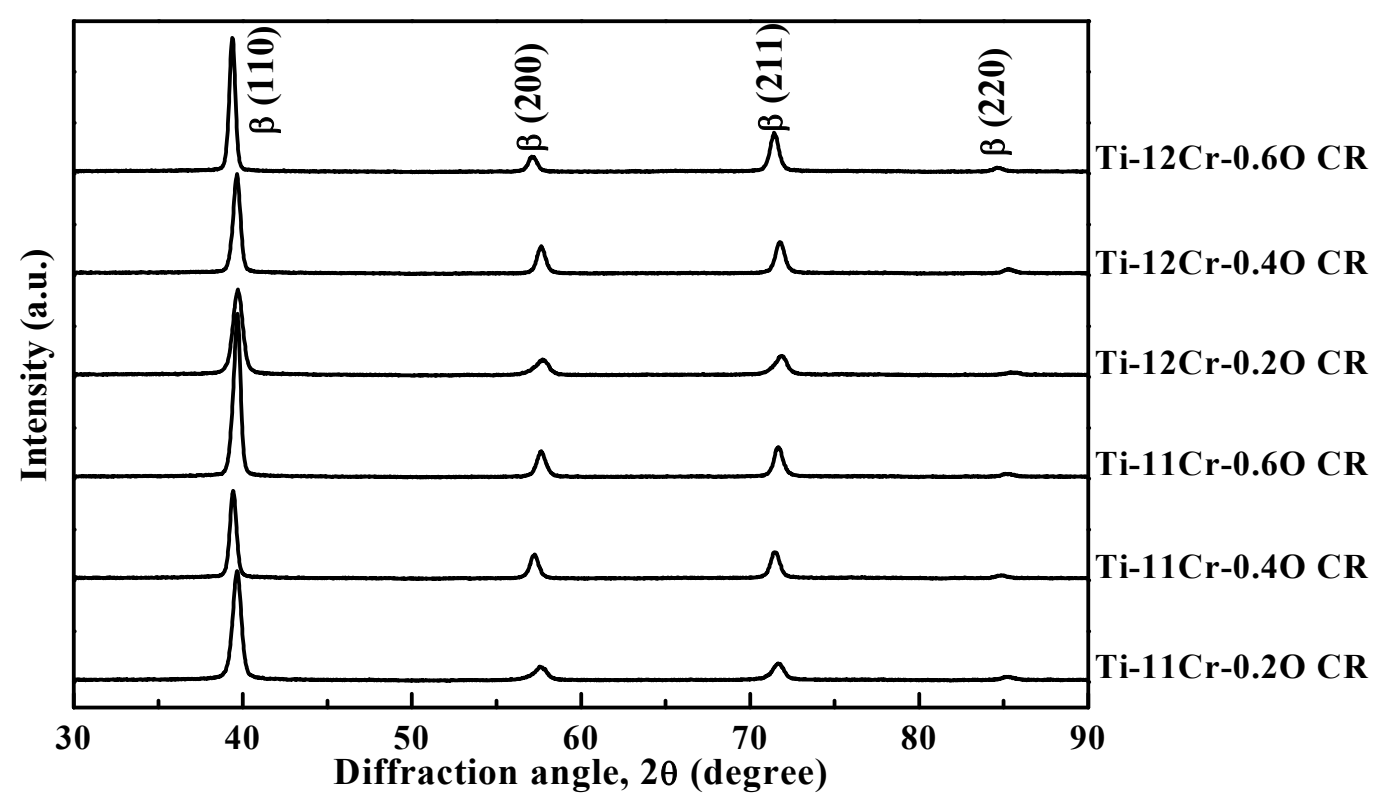

(b)

Fig. 2. XRD profiles of Ti-Cr-O alloys subjected to (a) solution treatment (ST) and (b) cold rolling (CR). 


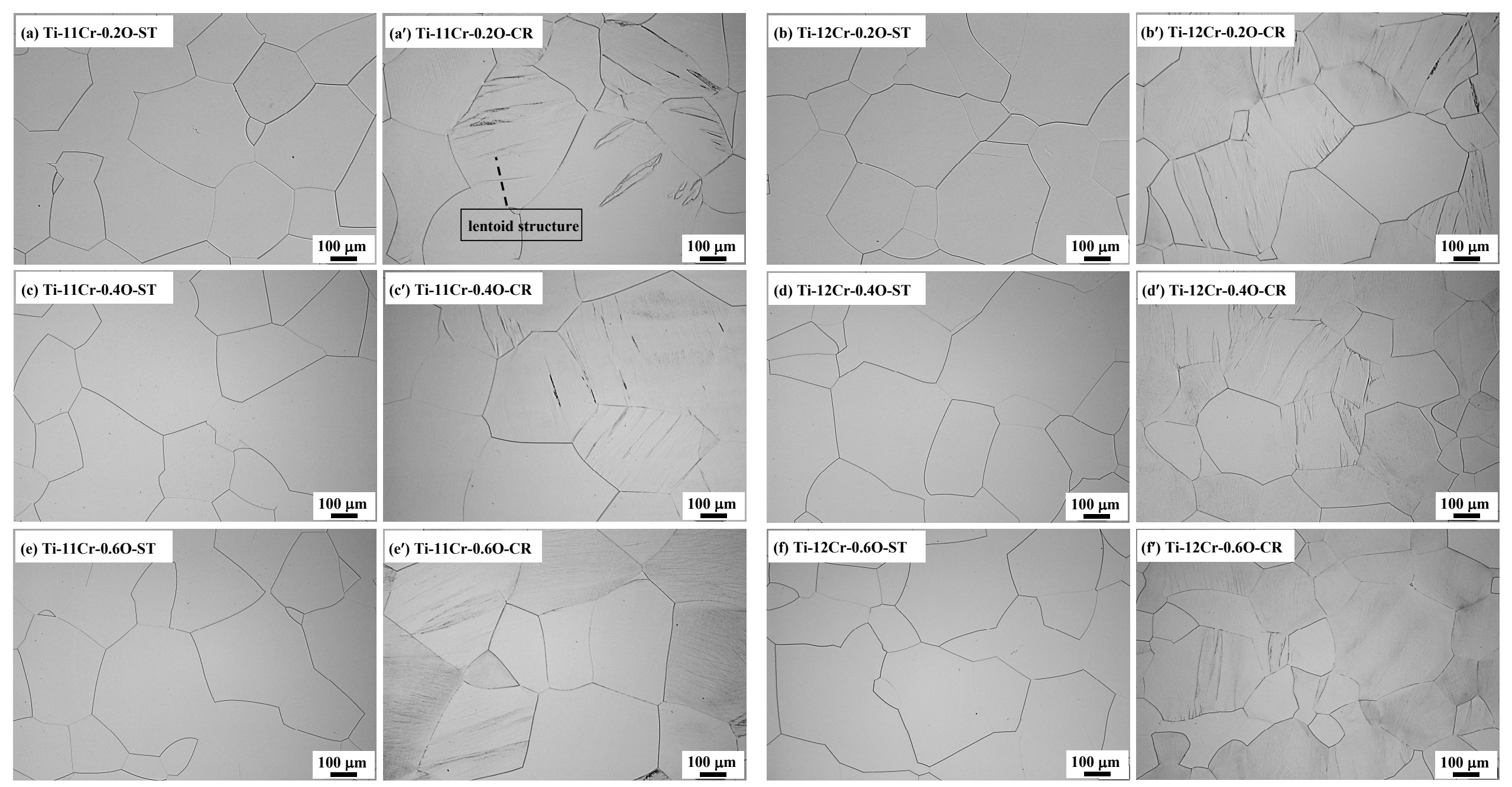

Fig. 3. Optical micrographs of Ti-Cr-O alloys subjected to solution treatment (ST) and cold rolling (CR). 


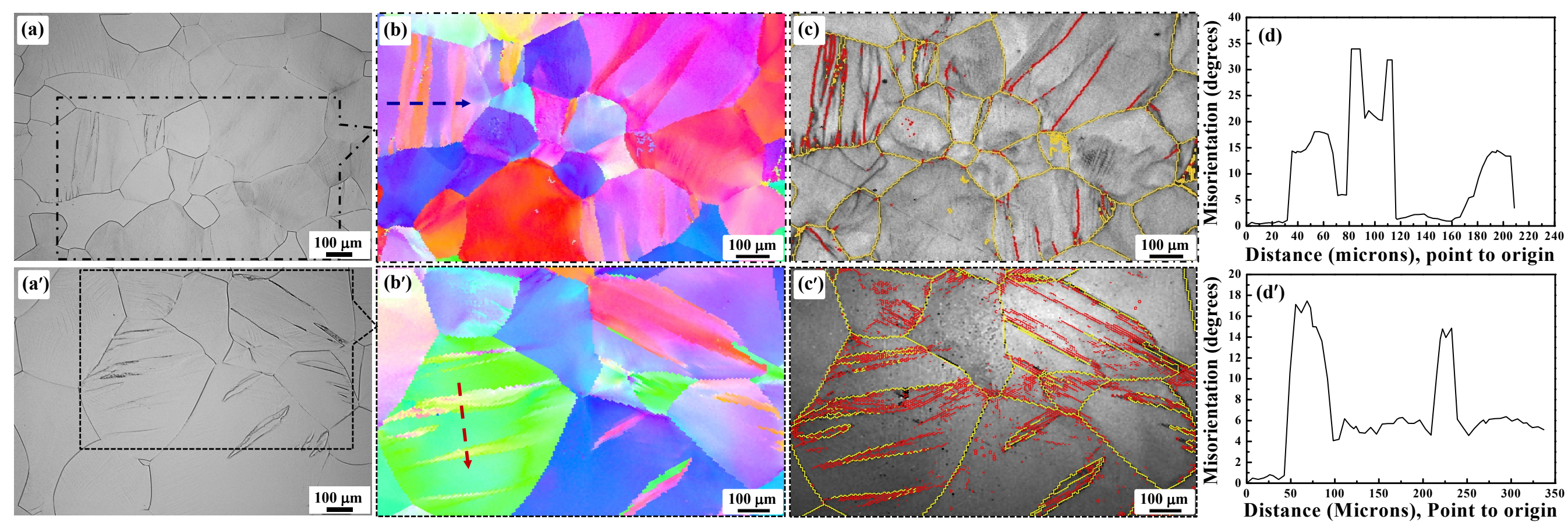

Fig. 4. EBSD analysis of Ti- $12 \mathrm{Cr}-0.6 \mathrm{O}(\mathrm{a}-\mathrm{d})$ and Ti- $11 \mathrm{Cr}-0.2 \mathrm{O}\left(\mathrm{a}^{\prime}-\mathrm{d}^{\prime}\right)$ alloys subjected to CR: (a, $\left.\mathrm{a}^{\prime}\right)$ optical micrographs, $\left(b, b^{\prime}\right)$ corresponding local orientation image map (OIM) figures, (c, $\left.c^{\prime}\right)$ GB maps showing boundaries with a misorientation of $10^{\circ}$ along the $<110>\beta$ direction (red lines), (d, $d^{\prime}$ ) misorientations relative to the first points along the blue and red arrows in (b) and ( $\left.b^{\prime}\right)$ respectively. 


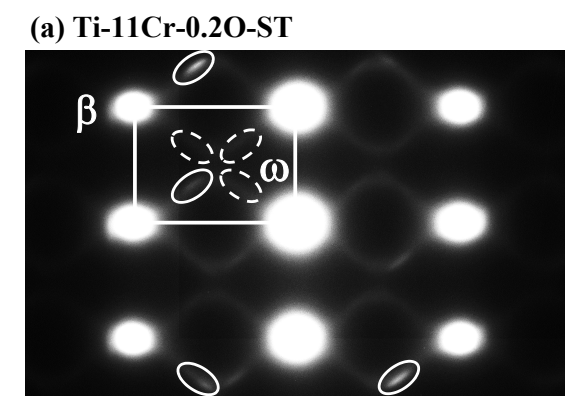

(a') Ti-11Cr-0.2O-CR
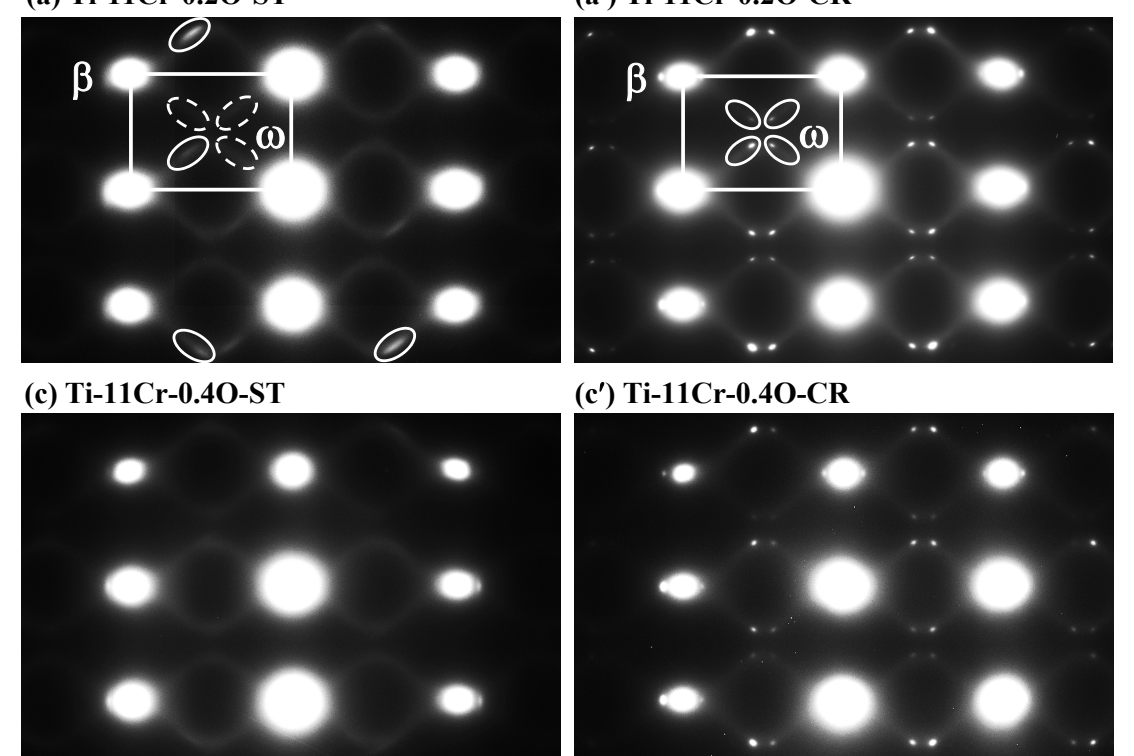

(c') Ti-11Cr-0.4O-CR

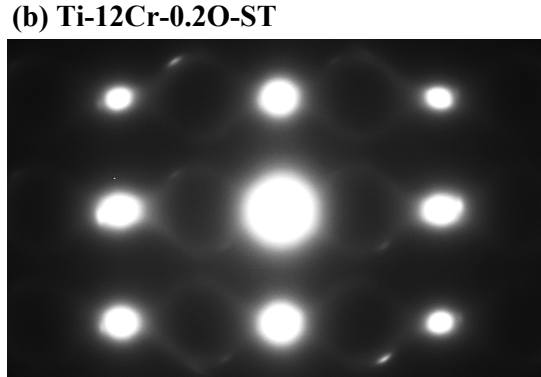

$\left(b^{\prime}\right)$ Ti-12Cr-0.2O-CR

(e) Ti-11Cr-0.6O-ST

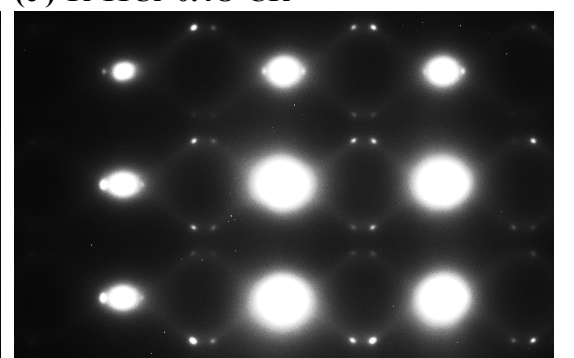

(d) Ti-12Cr-0.4O-ST
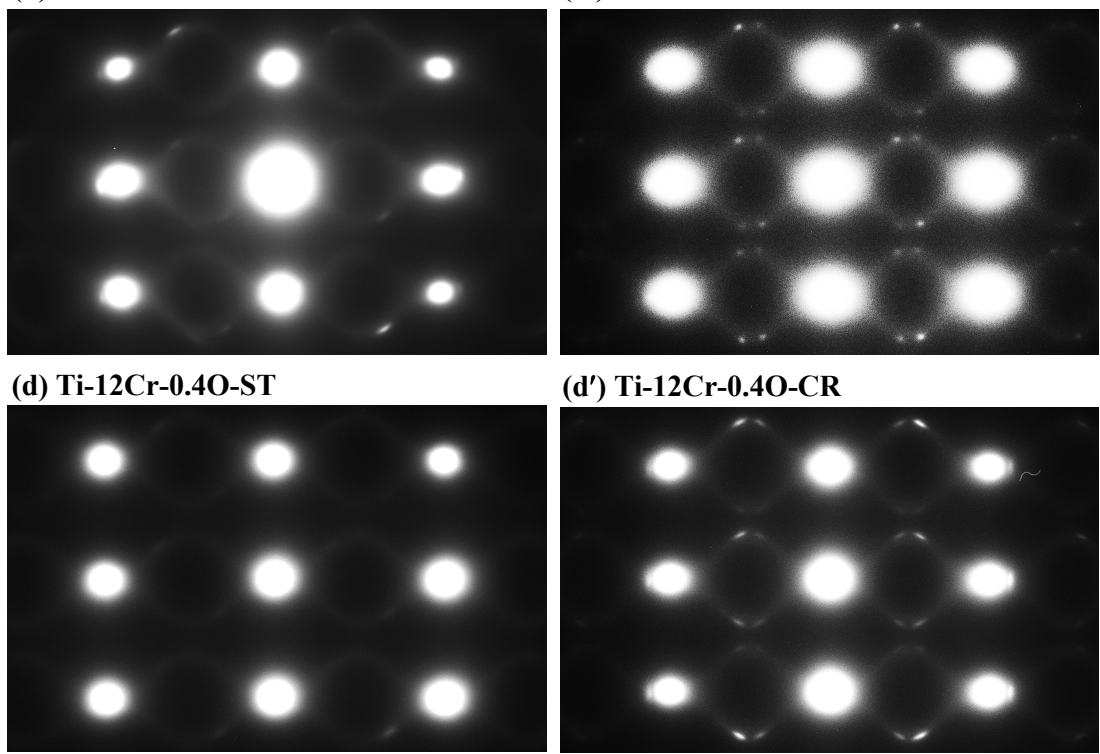

(d') Ti-12Cr-0.4O-CR

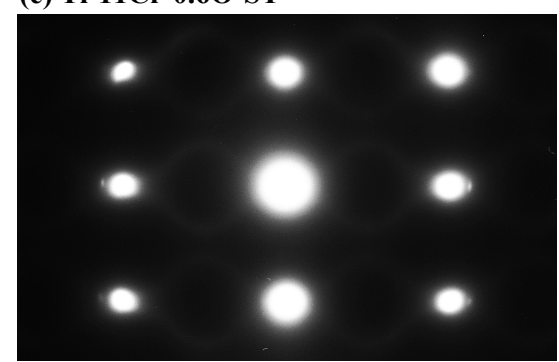

(e') Ti-11Cr-0.6O-CR

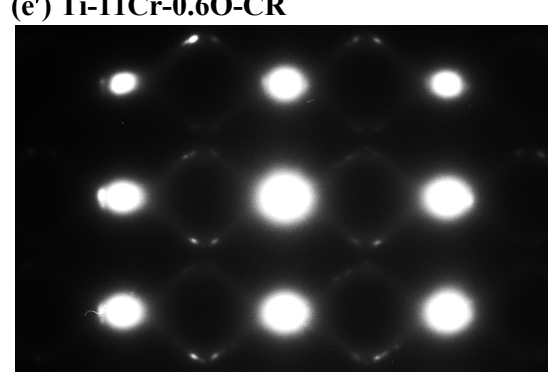

(f) Ti-12Cr-0.6O-ST

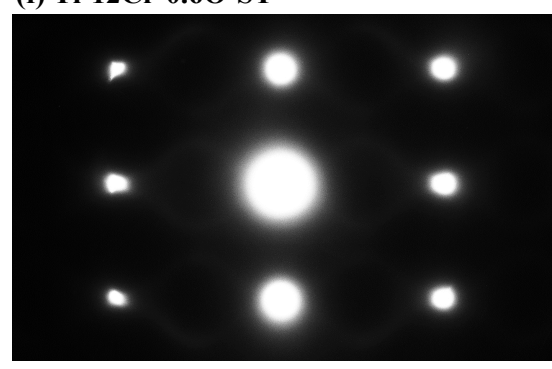

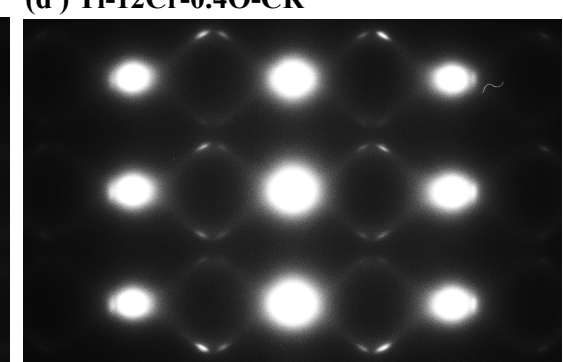

(f') Ti-12Cr-0.6O-CR

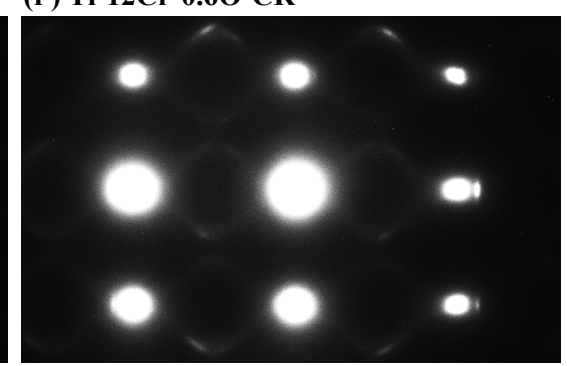

Fig. 5. Selected area electron diffraction patterns of Ti-(11,12)Cr- $(0.2,0.4,0.6) \mathrm{O}$ alloys subjected to ST and CR: (a) Ti-11Cr-0.2O-ST, (b) Ti-12Cr-0.2O-ST, (c) Ti-11Cr-0.4O-ST, (d) Ti-12Cr-0.4OST, (e) Ti-11Cr-0.6O-ST, (f) Ti-12Cr-0.6O-ST, (a') Ti-11Cr-0.2O-CR, (b') Ti-12Cr-0.2O-CR, (c') Ti-11Cr-0.4O-CR, (d') Ti-12Cr-0.4O-CR, (e') Ti-11Cr-0.6O-CR, (f') Ti-12Cr-0.6O-CR. The beam direction is parallel to [110] $\beta$. (The ellipse with solid line or dotted line indicates that the $\omega$ spot is visible or invisible respectively in Figs. 5a and $\mathrm{a}^{\prime}$.) 


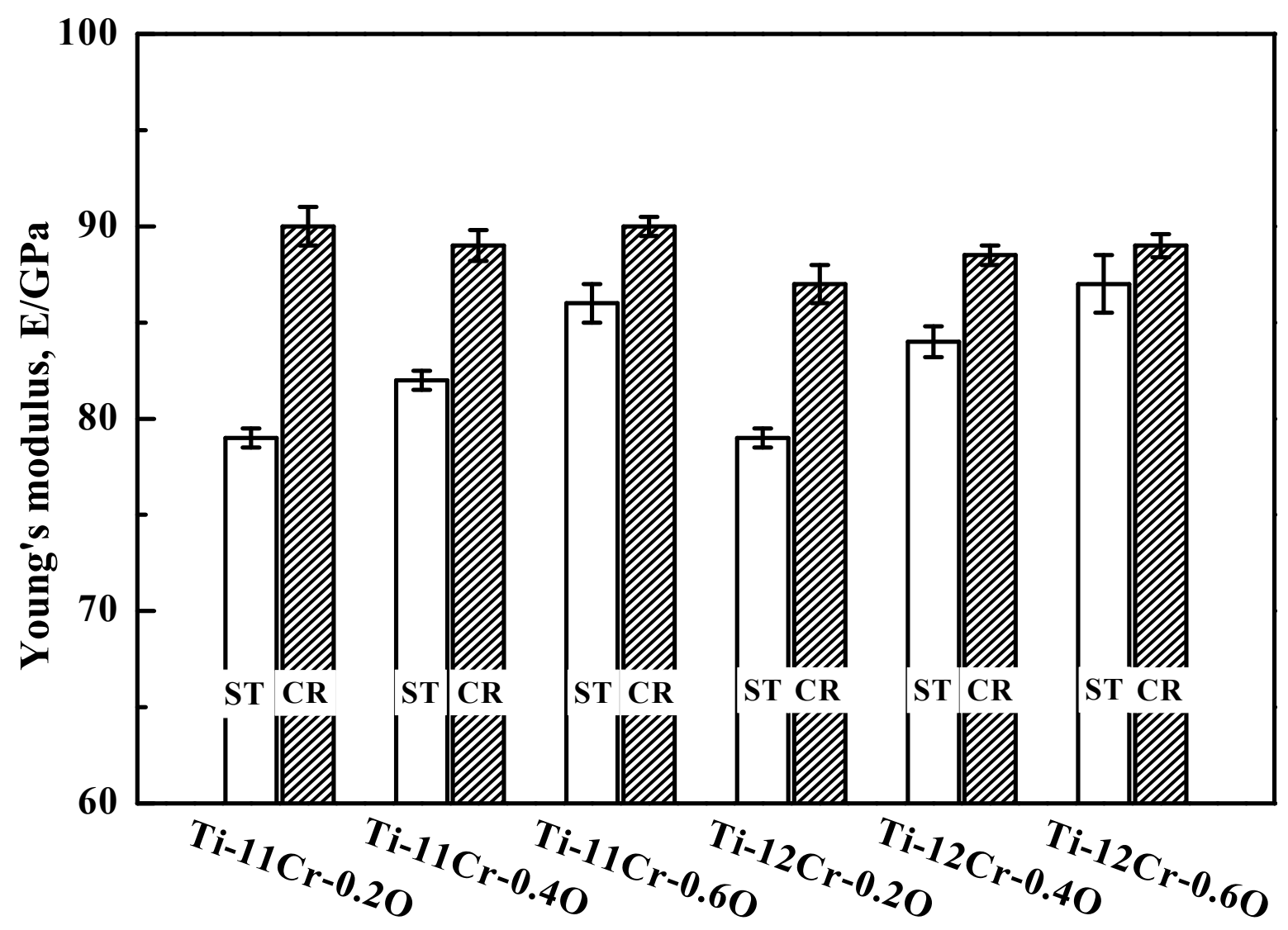

Fig. 6. Young's moduli of Ti- $(11,12) \mathrm{Cr}-(0.2,0.4,0.6) \mathrm{O}$ alloys subjected to ST and CR. 


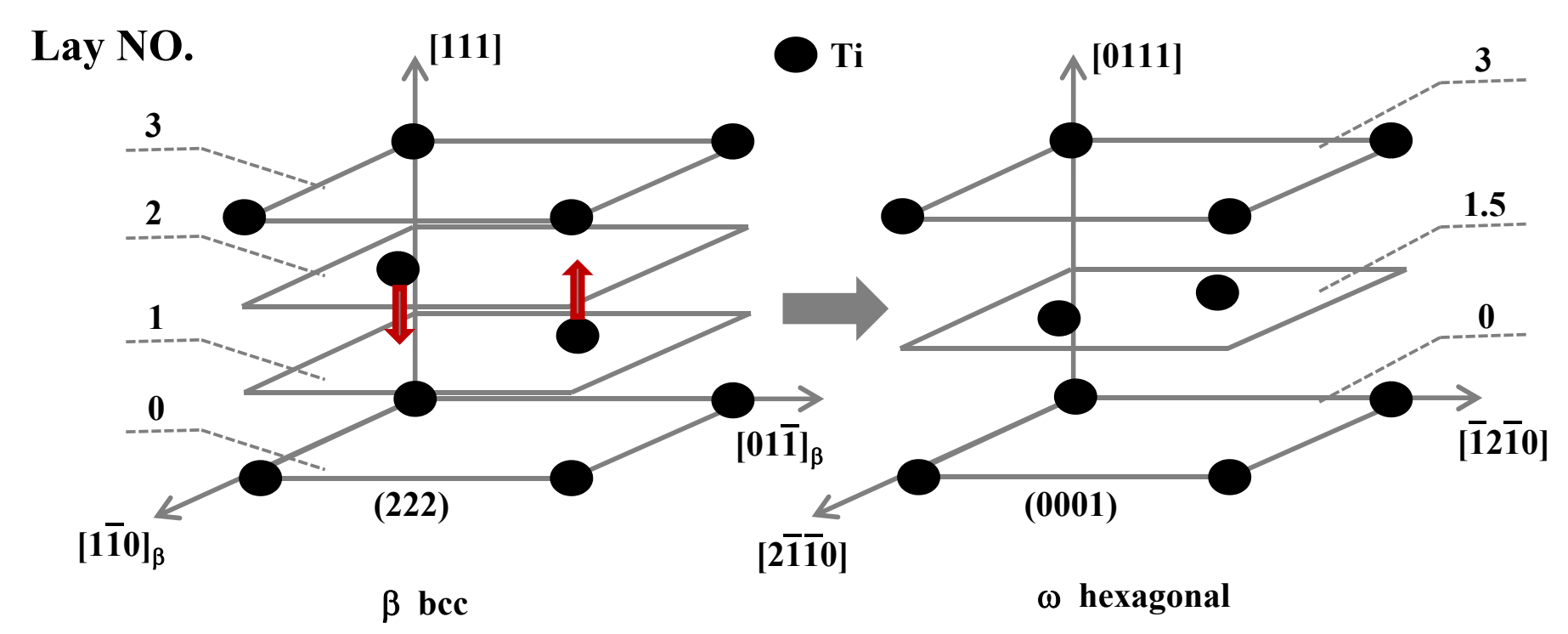

Fig. 7. Schematic illustration of lattice collapse mechanism (Banerjee and Mukhopadhyay, 2007). 


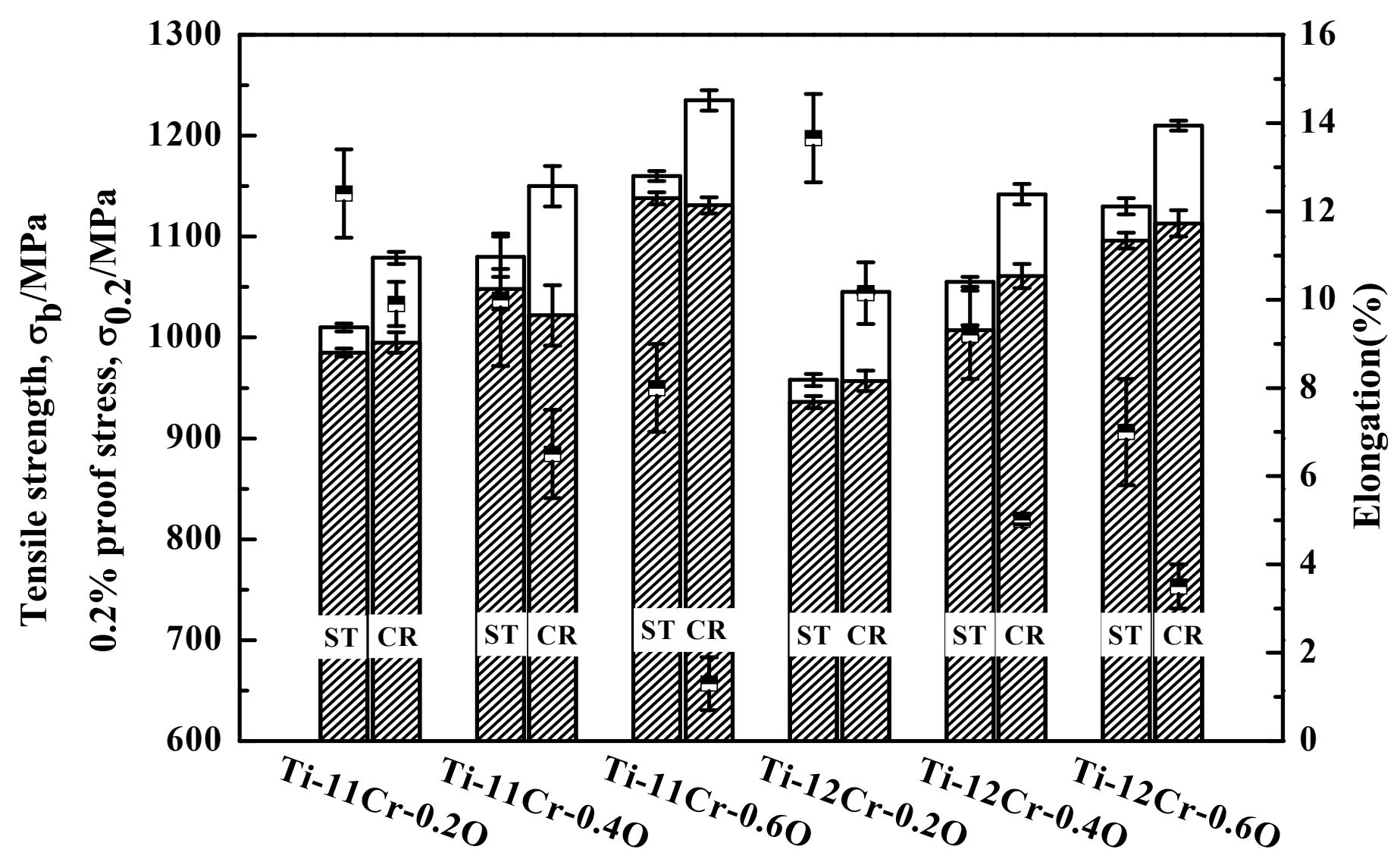

Fig. 8. Tensile properties of $\mathrm{Ti}-(11,12) \mathrm{Cr}-(0.2,0.4,0.6) \mathrm{O}$ alloys subjected to ST and CR. 


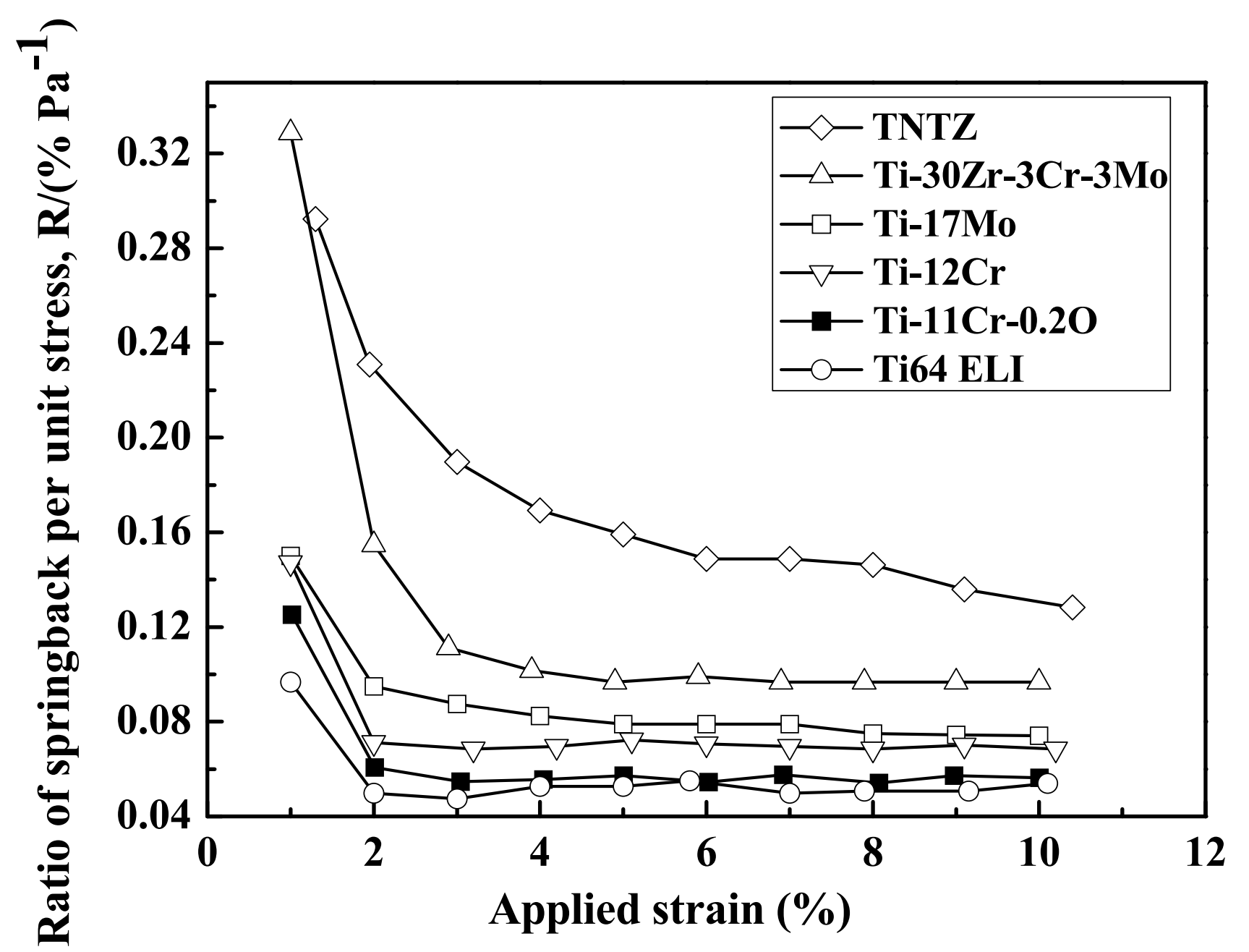

Fig. 9. Ratio of springback per unit stress $(\mathrm{R})$ as a function of applied strain for Ti-11Cr-0.2O, TNTZ (Kuroda et al., 1998), Ti-30Zr-3Cr-3Mo (Zhao et al., 2011b), Ti-17Mo (Zhao et al., 2012a), Ti-12Cr (Zhao et al., 2012b) and Ti64 ELI alloys subjected to ST. 
Table 1 Nominal and analyzed chemical compositions of Ti-Cr-O alloys (mass\%)

\begin{tabular}{lcccc}
\hline Alloy & $\mathrm{Cr}$ & $\mathrm{O}$ & $\mathrm{N}$ & $\mathrm{Ti}$ \\
\hline Ti-11Cr-0.2O & 11.3 & 0.22 & 0.0069 & Bal. \\
Ti-11Cr-0.4O & 11.1 & 0.41 & 0.0053 & Bal. \\
Ti-11Cr-0.6O & 11.2 & 0.60 & 0.0051 & Bal. \\
Ti-12Cr-0.2O & 12.1 & 0.21 & 0.0053 & Bal. \\
Ti-12Cr-0.4O & 12.0 & 0.39 & 0.0050 & Bal. \\
Ti-12Cr-0.6O & 11.7 & 0.59 & 0.0083 & Bal. \\
\hline
\end{tabular}


With the optimization of chromium and oxygen concentrations, the larger deformation-induced changeable Young's modulus was obtained in Ti- $11 \mathrm{Cr}-0.2 \mathrm{O}$ alloy, attributed to the formation of larger amount of deformation-induced $\omega$-phase.
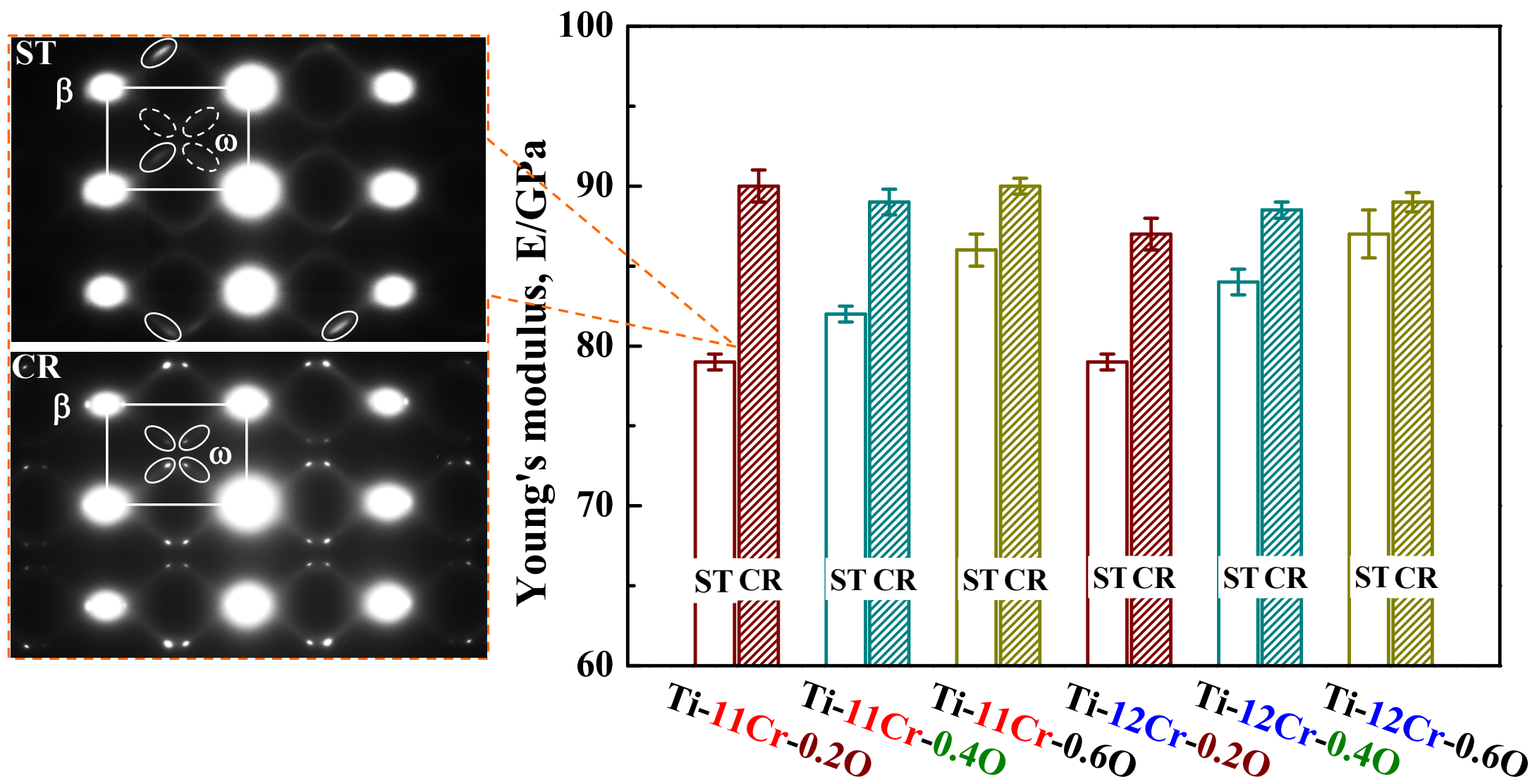

Abbreviation: ST—Solution treatment; $\mathrm{CR} —$ Cold rolling 